\title{
Aspectos epidemiológicos dos acidentes com material biológico em dentistas
}

\author{
Epidemiological aspects of accidents with biological material in dentists \\ Aspectos epidemiológicos de los accidentes con material biológico en odontólogos \\ Kátia Ferreira dos Santos ${ }^{1 *}$, Nilton José Fernandes Cavalcante ${ }^{2}$.
}

\begin{abstract}
RESUMO
Objetivo: Classificar aspectos epidemiológicos dos acidentes com material biológico em cirurgiões-dentistas (CD) e identificar as práticas de biossegurança adotadas. Métodos: Estudo transversal quantitativo, retrospectivo com dados obtidos no preenchimento de Formulário Específico (FE), da Comissão de Controle de Infecção Hospitalar $(\mathrm{CCIH})$ de hospital público em São Paulo, Brasil. Realizou-se entrevistas com questionários divididos em dois grupos de 20 dentistas, de 2008 a 2012, selecionados de 103 acidentes notificados. Resultados: CD do sexo feminino (77,71\%), idade média 33,6 anos. Trabalhavam em consultório particular (98\%), turno diurno (75,7\%), 8,9 anos de trabalho, $(68,9 \%)$ não notificaram o acidente e (32\%) relatou acidente anterior. Maioria dos acidentes ocorreu às sextas-feiras $(23,3 \%)$, exposição percutânea $(84,5 \%)$, contendo sangue $(56,3 \%)$ e com lúmen de agulha $(38,8 \%)$, mão esquerda $(46,7 \%)$, durante procedimentos (58,3\%), autoacidentes (75,7\%). Quanto aos EPI (Equipamento de Proteção Individual), destacaram-se luvas (86,4\%). O paciente-fonte era conhecido em $(87,4 \%),(91,3 \%)$ vacinados contra hepatite B, (58,3\%) receberam terapia antiretroviral (TARV) e $(45,6 \%)$ completaram o monitoramento. Conclusão: Acidentes ocorreram nas sextas-feiras, com exposição percutânea, contendo sangue no lúmen da agulha, mão esquerda, durante procedimentos e autoacidentes. EPI mais utilizado foram luvas. Após os acidentes, houve mudança na biossegurança.
\end{abstract}

Palavras-chave: Exposição ocupacional, Doenças transmissíveis, Contenção de riscos biológicos.

\begin{abstract}
Objective: Classify epidemiological aspects of accidents with biological material in dental surgeons (DC) and identify the biosafety practices adopted. Methods: Retrospective quantitative cross-sectional study with data obtained from completing the Specific Form (FE), of the Hospital Infection Control Commission (CCIH) public hospital in São Paulo, Brazil. Interviews were conducted with questionnaires divided into two groups of 20 dentists, 2008 to 2012, selected from 103 reported accidents. Results: female CD (77.71\%), mean age 33.6 years. Worked in a private practice $(98 \%)$, day shift $(75.7 \%), 8.9$ years of work, $(68.9 \%)$ did not report the accident. (32\%) reported previous accident. Most accidents occurred on Fridays (23.3\%), percutaneous exposure (84.5\%), containing blood (56.3\%) and with needle lumen (38.8\%), left hand (46.7 \%), during procedures (58.3\%), auto accidents (75.7\%). As for PPE (Personal Protective Equipment), gloves stood out (86.4\%). The source patient was known (87.4\%), (91.3\%) vaccinated against hepatitis B, (58.3\%) received antiretroviral therapy (ART) and (45.6\%) completed the monitoring. Conclusion: Accidents occurred on Fridays, with percutaneous exposure, containing blood in the needle lumen, left hand, during procedures and auto accidents. Most used PPE were gloves. After the accidents, there was change in biosafety.
\end{abstract}

Key words: Occupational exposure, Communicable diseases, Containment of biohazards.

\footnotetext{
${ }^{1}$ Secretaria de Estado da Saúde de São Paulo, São Paulo - SP. *E-mail: katiasantosdentista@gmail.com

2 Instituto de Infectologia Emílio Ribas, São Paulo - SP.
} 


\section{RESUMEN}

Objetivo: Clasificar aspectos epidemiológicos de accidentes con material biológico en odontólogos (EC) e identificar prácticas de bioseguridad adoptadas. Métodos: Estudio transversal cuantitativo retrospectivo con datos obtenidos de la cumplimentación del Formulario Específico (FE), de la Comisión de Control de Infecciones Hospitalarias $(\mathrm{CClH})$ de hospital público de São Paulo, Brasil. Las entrevistas se realizaron con cuestionarios divididos en dos grupos de 20 dentistas, 2008 a 2012, seleccionados entre 103 accidentes reportados. Resultados: Femenino (77,71\%), edad media 33,6 años. Trabajaban en consultorio privado (98\%), turno diurno (75,7\%), 8,9 años de trabajo, $(68,9 \%)$ no denunciaron el accidente y (32\%) informaron de accidente previo. Mayoría accidentes ocurrieron los viernes $(23,3 \%)$, exposición percutánea $(84,5 \%)$, sangre $(56,3 \%)$ y luz de aguja (38,8\%), mano izquierda $(46,7 \%)$, durante los procedimientos $(58,3 \%)$, accidentes automovilísticos (75,7\%). En cuanto a los EPI (Equipo de Protección Personal), destacaron los guantes $(86,4 \%)$. Paciente de origen era conocido en $(87,4 \%),(91,3 \%)$ vacunado contra la hepatitis $B,(58,3 \%)$ recibió terapia antirretroviral (TAR) y $(45,6 \%)$ completó el seguimiento. Conclusión: Accidentes ocurrieron los viernes, exposición percutánea, conteniendo sangre en la aguja ligera, mano izquierda, durante procedimientos y accidentes en sí. EPI más utilizado fueron los guantes. Después de los accidentes, hubo cambio en la bioseguridad.

Palabras clave: Exposición profesional, Enfermedades transmisibles, Contención de riesgos biológicos.

\section{INTRODUÇÃO}

O cirurgião dentista (CD) está exposto à contaminação de doenças infectocontagiosas, devido às infecções cruzadas, falta ou inadequação de biossegurança, cobertura vacinal incompleta, ausência correta de assepsia aos equipamentos e instrumentos com desinfetantes apropriados, descarte incorreto de materiais perfurocortantes e dejetos biológicos em lixo comum (MELO TRNB, et al., 2020).

Em 2020, a síndrome da Covid-19 tornou os profissionais da odontologia, expostos ao risco de infecção pelo SARS-CoV-2 e procedimentos de higiene associados ao uso correto de EPI foram os aliados na diminuição da transmissibilidade, além de evidenciar novas propostas comportamentais que incluíram maior cuidado com distanciamento social, protocolos de esterilização, ventilação de salas e higienização de superfícies com a finalide de reduzir o risco da doença (AMATO A, et al., 2020).

Nos procedimentos odontológicos há geração de aerossóis, respingos e partículas contaminantes, a partir da execução de atividades cirúrgicas em pessoas contaminadas; portanto, o medo da contaminação por HIV, hepatite $B(H B V)$ e hepatite $C(H C V)$ pelos $(C D)$ é frequente, devido à inalação de partículas de sangue aerossolizadas, durante procedimentos (ARTUZI FE, et al., 2009).

Os acidentes de trabalho, na odontologia são causados por instrumentos perfurocortantes contaminados com material biológico e são passíveis de transmissão de doenças como hepatites, sífilis e síndrome da imunodeficiência adquirida (AIDS), por meio de lesões cutâneas ou oculares. Tais acidentes podem comprometer a saúde física, mental e emocional dos profissionais com prejuízo nas relações sociais, familiares e trabalhistas (NOGUEIRA AS, et al., 2016).

A norma regulamentadora (NR- 32) foi criada pelo Ministério do Trabalho e Emprego com a intenção de reduzir danos aos trabalhadores e estabelece diretrizes para elaboração e implementação da necessidade do uso de EPI para evitar riscos de acidentes com perfurocortantes em pacientes contaminados, além de orientar a execução de teste sorológico para o profissional e o paciente-fonte (OLIVEIRA HR e RIBEIRO GM, 2019).

A NR- 32 estabelece medidas obrigatórias para a notificação do acidente de trabalho, porém, isso é negligenciado pelos profissionais dentistas que não desconhecem protocolo de imunização vacinal, em casos de acidentes e, não o fazem como forma preventiva (GABLER IG, et al., 2012).

A prevenção da exposição ocupacional impede a transmissão dos vírus das hepatites $\mathrm{B}, \mathrm{C}$ e do vírus HIV, porém quando o acidente acontece há medidas que devem ser tomadas imediatamente, a fim de prevenir infeccções e garantir a segurança do trabalho, como a imunização contra hepatite $B$ e terapia antirretroviral para o HIV (TARV) (CAVALCANTE NJF, et al., 2003). 
Para Nogueira AS, et al. (2016), não há um sistema de notificação de acidentes capaz de garantir o gerenciamento, possibilitar políticas públicas para diminuir as ocorrências, ter dados precisos para ajudar nas pesquisas e orientar trabalhadores, principalmente em situações que comprometam a saúde e causem danos. A subnotificação e a desinformação profissional sobre os registros impedem o conhecimento da amplitude dos acidentes, sobre como proceder no momento do acidente e seus reais prejuízos.

Condutas adequadas de biossegurança são norteadoras de proteção aos profissionais da odontologia e podem evitar acidentes com material biológico, infecções cruzadas, disseminação de doenças infectantes causadas por diversos vírus como o HBV, HBC, HIV, COVID-19 e outros (SANTOS KF e CAVALCANTE NJF, 2021).

O objetivo deste trabalho foi classificar os aspectos epidemiológicos dos acidentes com material biológico em cirurgiões-dentistas, caracterizar os acidentes ocupacionais e identificar o dia da semana de maior ocorrência dos acidentes.

\section{MÉTODOS}

Foi realizado um estudo transversal quantitativo retrospectivo obtido a partir de Formulário Específico (FE), com resposta voluntária aos dois questionários. O primeiro questionário era direcionado às práticas de biossegurança contendo informações pessoais e profissionais em odontologia e o outro questionário caracterizava os acidentes ocupacionais com material biológico, identificava qual o momento de maior ocorrência dos acidentes, grau de percepção, impacto das mudanças comportamentais após o acidente e foram pré-testados.

Aprovado pelo Comitê de Ética em Pesquisa (CEP), na Plataforma Brasil (Número CAAE: 15709913.4.0000.0061) e todos os participantes da pesquisa assinaram o termo de consentimento livre e esclarecido (TCLE).

O FE foi preenchido pela equipe da Comissão de Controle de Infecção Hospitalar (CCIH) de um hospital público em São Paulo, Brasil e os acidentes foram selecionados de 2008 a 2012. Foi organizado um banco de dados coletando os seguintes dados: identificação pessoal, dados profissionais, acidente anterior, acidente atual, tipo de acidente, material, instrumento, hora do acidente, motivo do acidente, EPI, histórico do paciente fonte (contaminante), histórico anterior do trabalhador acidentado, manejo clínico e retornos com acompanhamento a cada 6 semanas, 3 meses, 6 meses até 1 ano.

O critério de inclusão foi determinado pela notificação do dos profissionais acidentados, na CCIH do hospital de referência, que sofreram acidentes com perfurocortantes e material biológico contaminado, independentemente da especialidade odontológica e tempo de formado, no período de 2008 a 2012.

De 2008 a 2012 houve um número de 103 ( $n=103$ ) cirurgiões-dentistas, chamado de Grupo Geral (GG), atendidos por exposição ocupacional no referido hospital. Dentre esse total, $40 \quad(n=40)$ profissionais, designado como Grupo Selecionado (GS), responderam ao questionário semiestruturado, sendo que 20 acidentes ocorreram antes de 2011 e os demais após. Não houve atualização destes dados, pois a prestação de serviço ambulatorial passou por modificações estruturais e o atendimento foi indicado para postos de saúde, no local mais próximo onde os acidentados sofriam o acidente.

No período de 2011 e 2012 os dentistas que estavam sendo assistidos foram entrevistados pessoalmente, durante ao retorno ambulatorial e totalizaram 20 profissionais. Para cada profissional selecionado a partir de 2011, outro foi convidado, por telefone desde 2008 até que mais 20 dentistas fossem chamados e completassem o total de 40 profissionais.

Os profissionais selecionados neste estudo foram atendidos primeiramente, no Pronto-Socorro do hospital público de referência para doenças infecciosas, de acordo com as diretrizes pré-estabelecidas pelo Ministério da Saúde e tiveram seu retorno agendado para o ambulatório da CCIH e o FE foi preenchido por um médico. Em seguida, a equipe reavaliava a necessidade de continuidade ou não da quimioprofilaxia contra hepatite $\mathrm{B}$, hepatite $\mathrm{C}$ e vírus da imunodeficiência humana (HIV) e estabelecia o acompanhamento ambulatorial, de acordo com as variáveis epidemiológicas e os resultados das sorologias realizadas no hospital. 
As variáveis referentes à caracterização dos CD foram sociodemográficas, formação profissional, condições de trabalho, caracterização dos acidentes, informações sobre biossegurança e depois de selecionadas foram submetidas à análise descritiva e os dados coletados foram inseridos em banco de dados construído em um programa estatístico Statistical Package for the Social Sciences (SPSS versão 19.0) e tratados por meio de estatística descritiva, com cálculos de percentuais e frequências. Pode-se aplicar o teste do Qui - Quadrado de Pearson ou o teste Exato de Fisher para medir a discrepância entre as frequências observadas e as esperadas e quando necessário foi aplicado à correção de Yates (FIELD A, 2009).

\section{RESULTADOS}

O grupo que respondeu as entrevistas $(n=40)$ é representativo do grupo geral $(n=103)$ quanto à faixa etária, sexo, instituição, tempo na função e difere pelo menor número de profissionais que trabalhavam no período noturno (Tabela 1).

Tabela 1 - Informações sociodemográficas de cirurgiões-dentistas com exposição a material biológico acompanhados no ambulatório de acidentes (2008 a 2012). Grupo geral e grupo selecionado.

\begin{tabular}{|c|c|c|c|c|}
\hline Categoria & Variável & $\begin{array}{l}\text { Grupo geral } \\
\text { (GG) }\end{array}$ & $\begin{array}{c}\text { Grupo selecionado } \\
\text { (GS) }\end{array}$ & $\mathbf{p}^{\star}$ \\
\hline Total de participantes & & $\mathrm{N}=103$ & $\mathrm{~N}=40$ & \\
\hline \multirow{4}{*}{ Faixa Etária } & Mínimo em anos & 22 & 24 & \multirow{4}{*}{ ns } \\
\hline & Máximo em anos & 54 & 56 & \\
\hline & Média em anos & 33,6 & 36,5 & \\
\hline & Desvio padrão em anos & 7,9 & 9,1 & \\
\hline \multirow{2}{*}{ Sexo } & Feminino & $80(77,7 \%)$ & $32(80 \%)$ & \multirow{2}{*}{$\mathrm{ns}^{*}$} \\
\hline & Masculino & $23(22,3 \%)$ & $8(20 \%)$ & \\
\hline \multirow{2}{*}{ Instituição } & IIER & $2(1,9 \%)$ & $1(2,5 \%)$ & \multirow{2}{*}{$\mathrm{ns}^{*}$} \\
\hline & Particulares & $101(98,1 \%)$ & $39(97,5 \%)$ & \\
\hline \multirow{3}{*}{ Turno } & Diurno & $78(75,7 \%)$ & $37(92,5 \%)$ & \multirow{3}{*}{0,05} \\
\hline & Noturno & $25(24,3 \%)$ & $3(7,5 \%)$ & \\
\hline & Ambos & $3(2,9 \%)$ & $3(7,5 \%)$ & \\
\hline \multirow{3}{*}{ Tempo na função } & Mínimo em anos & 1,5 & 1 & \multirow{3}{*}{$\mathrm{ns}^{*}$} \\
\hline & Máximo em anos & 30 & 32,41 & \\
\hline & Média em anos & 8,9 & 14,7 & \\
\hline \multirow{3}{*}{$\begin{array}{l}\text { Notificou Medicina do } \\
\text { trabalho na primeira } \\
\text { consulta }\end{array}$} & Sim & $13(12,7 \%)$ & $5(12,5 \%)$ & \multirow{3}{*}{$\mathrm{ns}^{*}$} \\
\hline & Não & $71(68,9 \%)$ & $35(87,5 \%)$ & \\
\hline & Não mencionado & $19(18,4 \%)$ & $0,0 \%$ & \\
\hline \multirow{2}{*}{$\begin{array}{l}\text { Acidente prévio no } \\
(\mathrm{GG}=33) \text { e }(\mathrm{GS}=14)\end{array}$} & Sim & $33(32 \%)$ & $14(35 \%)$ & \multirow{2}{*}{$\mathrm{ns}^{*}$} \\
\hline & Não & $70(68 \%)$ & $26(65 \%)$ & \\
\hline \multirow{3}{*}{$\begin{array}{l}\text { Acompanhamento do } \\
\text { acidente prévio }\end{array}$} & Sim & $10(9,7 \%)$ & $4(29 \%)$ & \multirow{3}{*}{$\mathrm{ns}^{*}$} \\
\hline & Não & $22(21,4 \%)$ & $10(71 \%)$ & \\
\hline & Não mencionado & $01(3,0 \%)$ & $0,0 \%$ & \\
\hline \multirow{6}{*}{ Dia da semana } & Segunda & $9(8,7 \%)$ & $3(7,5 \%)$ & \multirow{6}{*}{$\mathrm{ns}^{*}$} \\
\hline & Terça & $17(16,5 \%)$ & $7(17,5 \%)$ & \\
\hline & Quarta & $16(15,5 \%)$ & $8(20 \%)$ & \\
\hline & Quinta & $15(14,5 \%)$ & $6(15 \%)$ & \\
\hline & Sexta & $24(23,3 \%)$ & $11(27,5 \%)$ & \\
\hline & Sábado & $22(21,3 \%)$ & $5(12,5 \%)$ & \\
\hline
\end{tabular}

Legenda: Teste de Qui-quadrado. $p>0,05$ não foi considerado significante (ns ${ }^{*}$.

Fonte: Santos KF e Cavalcante NJF, 2021.

No grupo geral a faixa etária variou entre a idade mínima de 22 anos, a máxima de 54 anos, a (média = 33,6) e o desvio padrão de 7,9 anos. A predominância dos profissionais foi do sexo feminino, em instituições particulares, turno de trabalho de maior ocorrência desses eventos foi o diurno, com tempo médio de trabalho na função de cirurgião-dentista de 8,9 anos e a medicina do trabalho foi pouco notificada pelos profissionais, em ambos os grupos. 
A maioria não havia sofrido acidente prévio e, dos que foram acometidos, somente 10 profissionais do GG fizeram acompanhamento ambulatorial. $O$ dia da semana mais propenso ao acometimento com acidentes, pelos profissionais foi à sexta-feira que mostrou maior ocorrência dos acidentes.

Tabela 2 - Caracterização de acidentes em cirurgiões-dentistas com exposição a material biológico acompanhados no ambulatório de acidentes (2008 a 2012). Grupo geral e grupo selecionado.

\begin{tabular}{|c|c|c|c|c|}
\hline $\begin{array}{c}\text { Categoria } \\
\text { Total de participantes }\end{array}$ & \multicolumn{2}{|c|}{ Variável } & $\begin{array}{c}\text { Participantes (GG) } \\
\mathrm{N}=103\end{array}$ & $\begin{array}{c}\text { Participantes (GS) } \\
\mathrm{N}=40\end{array}$ \\
\hline & \multicolumn{2}{|c|}{ Percutâneo } & $87(84,5 \%)$ & $36(90 \%)$ \\
\hline & \multicolumn{2}{|c|}{ Mucosa oral } & $2(1,9 \%)$ & $1(2,5 \%)$ \\
\hline Tipo & \multicolumn{2}{|c|}{ Mucosa ocular } & $8(7,8 \%)$ & $3(7,5 \%)$ \\
\hline & \multicolumn{2}{|c|}{ Pele integra } & $5(4,9 \%)$ & $0,0 \%$ \\
\hline & \multicolumn{2}{|c|}{ Outro } & $1(0,9 \%)$ & $0,0 \%$ \\
\hline \multirow{4}{*}{ Material } & \multicolumn{2}{|c|}{ Sangue } & $58(56,3 \%)$ & $21(52,5 \%)$ \\
\hline & \multicolumn{2}{|c|}{ Fluido com sangue } & $4(3,9 \%)$ & $7(17,5 \%)$ \\
\hline & \multicolumn{2}{|c|}{ Outro Fluido } & $15(14,6 \%)$ & $3(7,5 \%)$ \\
\hline & \multicolumn{2}{|c|}{ Ignorado } & $26(25,2 \%)$ & $9(22,5 \%)$ \\
\hline \multirow{5}{*}{ Instrumento } & \multicolumn{2}{|c|}{ Agulha oca } & $40(38,8 \%)$ & $13(32,5 \%)$ \\
\hline & \multicolumn{2}{|c|}{ Agulha sutura } & $5(4,9 \%)$ & $2(5 \%)$ \\
\hline & \multicolumn{2}{|c|}{ Lâmina } & $4(3,9 \%)$ & $0,0 \%$ \\
\hline & \multicolumn{2}{|c|}{ Ignorado } & $54(52,4 \%)$ & $0,0 \%$ \\
\hline & \multicolumn{2}{|c|}{ Outros* } & $0,0 \%$ & $25(62,5 \%)$ \\
\hline \multirow{5}{*}{ Topografia do acidente } & \multicolumn{2}{|c|}{ Mão direita } & $28(27,2 \%)$ & $13(32,5 \%)$ \\
\hline & \multicolumn{2}{|c|}{ Mão esquerda } & $48(46,7 \%)$ & $21(52,5 \%)$ \\
\hline & \multicolumn{2}{|c|}{ Olhos } & $4(3,9 \%)$ & $5(12,5 \%)$ \\
\hline & \multicolumn{2}{|c|}{ Coxa } & $2(1,9 \%)$ & $1(2,5 \%)$ \\
\hline & \multicolumn{2}{|c|}{ Não informado } & $21(20,3 \%)$ & $0,0 \%$ \\
\hline \multirow{4}{*}{ Momento do acidente } & \multicolumn{2}{|c|}{ Durante } & $60(58,3 \%)$ & $26(65 \%)$ \\
\hline & \multicolumn{2}{|c|}{ Após } & $36(35,0 \%)$ & $13(32,5 \%)$ \\
\hline & \multicolumn{2}{|c|}{ Ambos } & $1(1,0 \%)$ & $1(2,5 \%)$ \\
\hline & \multicolumn{2}{|c|}{ Não Informado } & $6(5,8 \%)$ & $0,0 \%$ \\
\hline & & Sim & $27(26,2 \%)$ & $11(27,5 \%)$ \\
\hline & Expressāo & Não & $76(73,8 \%)$ & $29(72,5 \%)$ \\
\hline & Áaya & Sim & $77(74,8 \%)$ & $30(75 \%)$ \\
\hline & Agua & Não & $26(25,2 \%)$ & $10(25 \%)$ \\
\hline Medida apos 0 acidente & & Sim & $63(61,2 \%)$ & $25(62,5 \%)$ \\
\hline & Sabáo & Não & $40(38,8 \%)$ & $15(37,5 \%)$ \\
\hline & & Sim & $47(45,6 \%)$ & $19(47,5 \%)$ \\
\hline & Antisséptico & Não & $56(54,4 \%)$ & $21(52,5 \%)$ \\
\hline & Autoaci & & $78(75,7 \%)$ & $26(65 \%)$ \\
\hline & Movimento d & ciente & $3(2,9 \%)$ & $3(7,5 \%)$ \\
\hline & Movimento & olega & $2(1,9 \%)$ & $1(2,5 \%)$ \\
\hline Causa do Acidente & Descarte in & uado & $3(2,9 \%)$ & $3(7,5 \%)$ \\
\hline & Reenc & & $9(8,7 \%)$ & $3(7,5 \%)$ \\
\hline & Out & & $8(7,8 \%)$ & $4(10 \%)$ \\
\hline
\end{tabular}

Legenda: $\left(^{*}\right)$ refere-se a: curetas, agulhas anestésicas, fio ortodôntico, lima endodôntica.

Fonte: Santos KF e Cavalcante NJF, 2021.

O tipo de acidente foi percutâneo e o material biológico envolvido foi sangue. Quanto ao instrumento envolvido nos acidentes foi agulha oca e a topografia estudada revelou que a mão esquerda foi a mais 
acometida, durante os procedimentos. Um terço dos profissionais realizou expressão no local acidentado como medida pós-exposição ao acidente. Autoacidente mostrou ser a causa principal dos acidentes.

Quanto às informações sobre biossegurança para os profissionais selecionados temos na Tabela 3 que lavagem das mãos antes de procedimentos clínicos (95\%) com utilização de sabão (45\%), troca de luvas (90\%), quando perfuradas (90\%) fazem parte de um protocolo de paramentação, seguido da adesão da maioria dos profissionais do grupo GS.

Tabela 3 - Informações sobre biossegurança dos 40 profissionais acidentados com exposição a material biológico (2008 a 2012) e uso de EPI do GG e GS.

\begin{tabular}{|c|c|c|c|c|}
\hline \multicolumn{2}{|c|}{ Categoria } & Variável & $\begin{array}{l}\text { Participantes } \\
\text { (GG) }\end{array}$ & $\begin{array}{l}\text { Participantes } \\
\text { (GS) }\end{array}$ \\
\hline \multicolumn{2}{|c|}{ Total de participantes } & & $\mathrm{N}=103$ & $\mathrm{~N}=40$ \\
\hline \multicolumn{2}{|c|}{ Pacientes atendidos em média por dia } & De 11 a 20 & -- & $17(42,5 \%)$ \\
\hline \multicolumn{2}{|c|}{$\begin{array}{l}\text { Lavagem das mãos antes de procedimentos } \\
\text { clínicos }\end{array}$} & Sim & -- & $38(95 \%)$ \\
\hline \multicolumn{2}{|c|}{ Uso de luvas descartáveis } & Sim & -- & $40(100 \%)$ \\
\hline \multicolumn{2}{|c|}{$\begin{array}{l}\text { Lavagem das mãos antes de procedimentos } \\
\text { cirúrgicos }\end{array}$} & Não & -- & $2(5 \%)$ \\
\hline \multicolumn{2}{|c|}{ Qual material utilizado } & Sabão & -- & $18(45 \%)$ \\
\hline \multicolumn{2}{|c|}{ Utilização de produto especial, após acidente } & Antisséptico & -- & $20(50 \%)$ \\
\hline \multicolumn{2}{|c|}{ Uso de luvas cirúrgicas } & $\begin{array}{l}\text { Não executam } \\
\text { cirurgia }\end{array}$ & -- & $2(5 \%)$ \\
\hline \multicolumn{2}{|c|}{$\begin{array}{l}\text { Já sofreu algum tipo de exposição em } \\
\text { procedimento }\end{array}$} & Sim & -- & $40(100 \%)$ \\
\hline \multicolumn{2}{|c|}{ Tipo de exposição } & Percutâneo & -- & $36(90 \%)$ \\
\hline \multicolumn{2}{|c|}{ Protocolo de paramentação } & Sim & -- & $32(80 \%)$ \\
\hline \multicolumn{2}{|c|}{ Uso de duplas luvas } & Não & -- & $28(70 \%)$ \\
\hline \multicolumn{2}{|c|}{ Tem percepção de perfuração de luvas } & Sim & -- & $36(90 \%)$ \\
\hline \multicolumn{2}{|c|}{ Efetua a troca das luvas } & Sim & -- & $36(90 \%)$ \\
\hline \multicolumn{2}{|c|}{ Mão dominante de trabalho } & Destro & -- & $35(87.5 \%)$ \\
\hline \multirow{6}{*}{ USO de EPI } & \multirow{2}{*}{ Luvas } & Sim & $89(86,4 \%)$ & $32(80 \%)$ \\
\hline & & Não & $14(13,6 \%)$ & $08(20 \%)$ \\
\hline & \multirow{2}{*}{ Máscara } & Sim & $54(52,4 \%)$ & $19(47,5 \%)$ \\
\hline & & Não & $49(47,6 \%)$ & $21(52,5 \%)$ \\
\hline & \multirow{2}{*}{ Sem EPI } & Sim & $10(9,7 \%)$ & $4(10 \%)$ \\
\hline & & Não & $93(90,3 \%)$ & $36(90 \%)$ \\
\hline
\end{tabular}

Fonte: Santos KF e Cavalcante NJF, 2021.

Quanto à variável "Uso de EPI", os elementos de biossegurança utilizados por ambos os grupos foram Luvas, Máscara e Sem EPI. Essas informações foram preenchidas pelos profissionais, na FE do acidente, nos dois grupos (GG e GS). As demais categorias apresentadas na Tabela 3 foram preenchidas somente pelo GS no momento da entrevista.

As luvas descartáveis foram as mais citadas como o EPI mais utilizado pelos profissionais $(86,4 \%)$, seguido de máscaras (52,4\%) e 9,7\% se encontravam sem nenhuma paramentação, no grupo GG. Após os acidentes, $50 \%$ dos profissionais, do GS, utilizaram antissépticos e somente dois profissionais (5\%) não lavavam as mãos, pois não realizavam procedimentos cirúrgicos. Do restante, $100 \%$ utilizavam luvas cirúrgicas descartáveis. Em 87,5\% dos profissionais entrevistados, a mão direita (destra) é a eleita para o trabalho.

A Figura 1 destaca as sextas-feiras como o dia da semana em que ocorre a maioria dos acidentes. Os parágrafos seguintes justificam o gráfico explicativo dos acidentes notificados e relatados nas entrevistas dos 
40 profissionais selecionados (GS), onde se apresentam os dias da semana e o número de profissionais envolvidos. A cor vermelha representa o GG e a cor azul destinou-se ao GS.

A necessidade de evidenciar os acidentes em dias semanais se deve ao fato de haver pouca literatura que esclareça, na odontologia, tais relatos o que pode dar maior visibilidade à situação e providenciar tomadas de atitudes profissionais, orientações em entidades de classe mais detalhadas, com conscientização para minimizar as ocorrências de forma preventiva e incentivar o uso de EPI, principalmente, às sextas-feiras.

Diferentemente, os casos de infarto do miocárdio, relatados na literatura, acontecem com maior incidência às segundas-feiras, de forma mais frequente do que aos finais de semana, mostrando que essas ocorrências podem estar relacionadas à diminuição de carga estressora seguida da retomada de preocupações nesse dia (SANTOS KF, 2014).

Figura 1 - Gráfico representativo do dia da semana que ocorreu o maio número de acidentes.

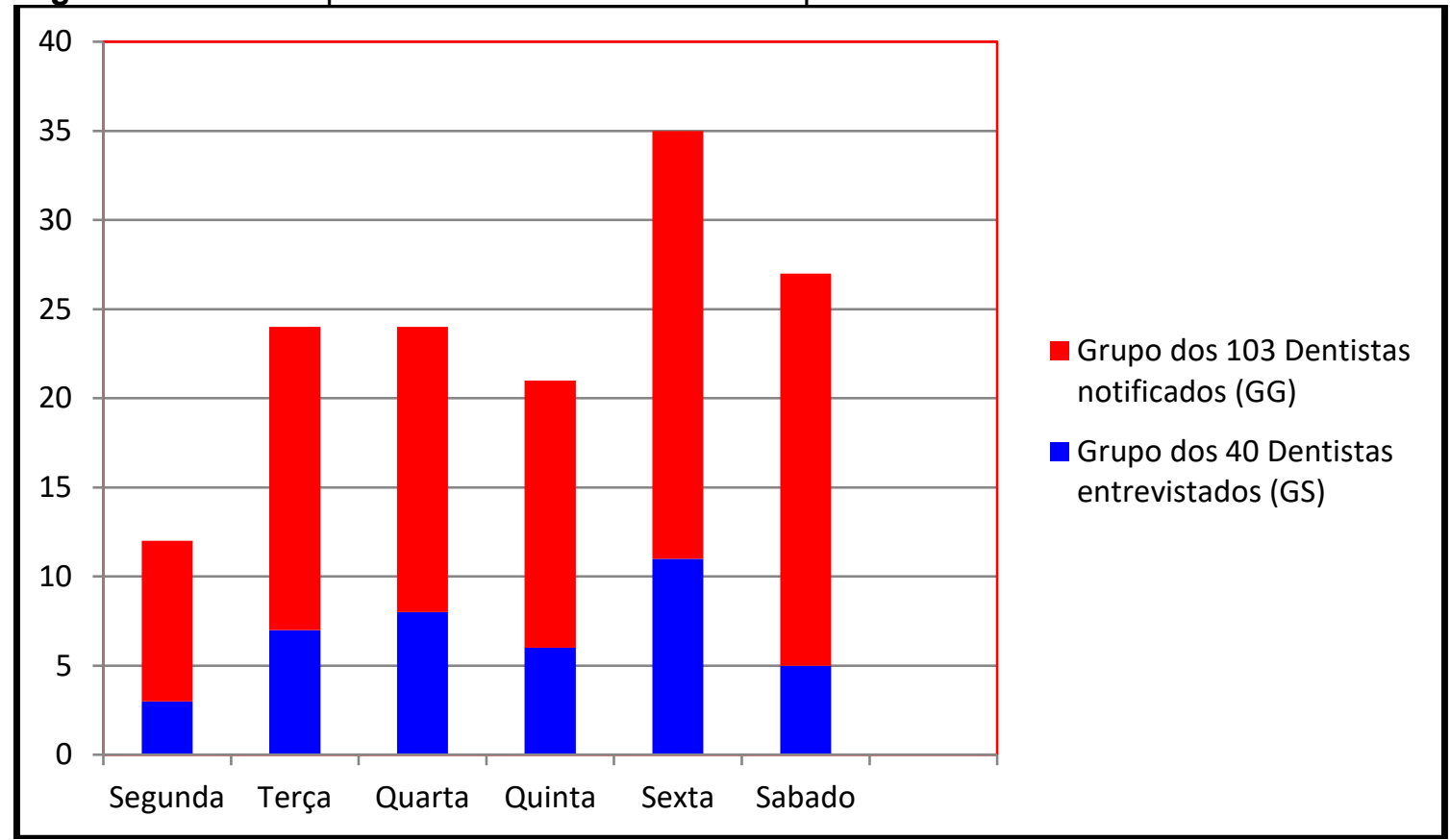

Fonte: Santos KF e Cavalcante NJF, 2021.

No GG, houve predominância dos acidentes, na sexta-feira, com 24 (23,3\%) notificações e correspondência com 11 (27,5\%) acidentes, no GS, que equivaleu quase à metade dos acidentes notificados do GG e evidenciou os fatores estressantes do trabalho com sobrecarga, durante a semana.

A segunda-feira mostrou ser o dia de menor destaque frente à notificação dos acidentes com $9(8,7 \%)$ e 3 $(7,5 \%)$ respectivamente, representado no GG e GS. Provavelmente, este fato se deve após um dia de descanso, com diminuição de estresse e de cargas emocionais decorrentes do próprio trabalho.

\section{DISCUSSÃO}

O sangue é um dos materias biológicos que quando contaminado pode expor os trabalhadores da saúde a vários agentes causadores de doenças, sendo que as de maior risco são: AIDS, hepatite $B$ e hepatite $C$ que podem acontecer, a partir de acidentes com perfurocortantes ou respingos em mucosas. A partir de 1980, a exposição ocupacional e a provável soroconversão dos trabalhadores da saúde vem tomando significado diferenciado com a finalidade de reduzir acidentes e documentar os riscos para tornar a informação consciente a todos os profissionais da saúde (ALMEIDA CAF e BENATTI MCC, 2007).

Silva LN, et al. (2011) ressaltam que há, na literatura muitas informações sobre métodos de transmissão sobre o vírus HIV, maneiras de prevenção, controle de infecção, por meio das normas de biossegurança que devem ser utilizadas em todos os pacientes indistintamente, como forma de diminuir o estigma da AIDS. 
Em 2020, na odontologia os tratamentos tiveram foram restritos a urgências e emergências odontológicas em todo o mundo, como forma de preventiva por conta das contaminações com o coranavírus, causador da COVID-19 que pode se espalhar com partículas aerossolizadas geradas em consultório. Medidas de biossegurança, distanciamento social adequado, aferição de temperatura foram fundamentais para salvaguardar profissionais e suas equipes, a fim de evitar a contaminação da doença (SANTOS KF e BARBOSA M, 2020).

A produção de aerossóis e respingos produzidos pelo uso de instrumentos rotatórios, em procedimento de odontologia, quando associados ao tamanho das partículas funcionam como veículos capazes de contaminar pela condução de vírus, bactérias, fungos e sangue. Com base nestas variáveis o uso de máscara descartáveis tipo FFP3 (peça facial filtrante de nível 3, de acordo com as normas européias), são indicadas como EPI pela capacidade elevada de filtragem, evitam contaminação cruzada e permitem proteção aos profissionais (COULTHARD P, 2020).

Em um estudo retrospectivo envolvendo acidentes profissionais, a maioria dos acidentados era auxiliar de enfermagem e uma pequena parte eram dentistas. Os acidentes na enfermagem ocorreram no turno da manhã, com exposição percutânea por meio de recapeamento de agulhas e sangue. O estudo sugere que maior engajamento de políticas públicas, fiscalização das normas regulatórias e conscientização dos profissionais pode ser um meio de práticas segura de trabalho com redução de acidentes (KHALIL SS, et al., 2015).

Para Kotze MJ e Labuschagn W (2014) as exposições percutâneas são causadas, quando há ferimentos, por objetos pontiagudos que rompem a pele e acontecem durante o tratamento dentário, porém os riscos de transmissão de doenças causadas por agulhas são proporcionais à quantidade, profundidade, tamanho e tipo de agulhas utilizadas. Para os autores, o problema é a subnotificação de acidentes causadas pelas exposições, conhecimento da presença de sangue no lúmen e superfície da agulha anestésica que podem contribuir de forma segura, no processo educacional dos dentistas para notificação de acidentes. Um dos aspectos importantes nos protocolos pós-exposição inclui a notificação de acidentes ao Serviço de Medicina do Trabalho (MARTINS AMEBL, et al., 2010).

Os profissionais que trabalham em instituições públicas são obrigados a notificar o acidente, pois existe um local normativo. Porém, para profissionais que atuam em consultório ou clínicas particulares, o mesmo não acontece, o que desencadeia a subnotificação (SANTOS KF, 2014).

A Norma Regulamentadora 32 estabelece a notificação obrigatória de acidentes com objetos perfurocortantes, mas muitas vezes os profissionais não notificam e mostram a falta de importância atribuída aos acidentes de risco transmissível, que aumentam à medida que o trabalhador passa por dificuldades em acessar setores de saúde ocupacional, com esta finalidade. A subnotificação dificulta as ações de políticas públicas, promoção da saúde e prevenção de doenças como as Hepatites Virais B e C (TIBÃES HBB, et al., 2014).

No estudo de Santos KF (2014) os EPI mais usados pelos dentistas foram às luvas descartáveis no que se refere ao (GG) e ao (GS), porém uma pequena parcela de profissionais relatou que não usava nenhum EPI que contribuiu para o acidente. De acordo, com Marziale MHP, et al. (2007) as luvas funcionam como uma barreira protetiva capaz de reduzir a contaminação pelo sangue, proteger os profissionais de riscos de inoculação de vírus com perfurocortantes, embora a contaminação ocupacional dependa da quantidade de sangue introduzido, profundidade da lesão e grau de contato profissional.

$\mathrm{Na}$ odontologia, há uma feminilização crescente a algumas décadas, enfatizando a presença de mulheres no mercado, com predomínio de dentistas jovens, até 30 anos, principalmente, no estado de São Paulo, com trabalho clínico e/ou de especialistas, atuando em consultórios particulares, jornada de trabalho em torno de 44 horas/semanais, duplo vínculo empregatício (rede pública e privada) com ganho familiar de até sete salários-mínimos (MOYSÈS SJ, 2003).

Almeida CAF e Benatti MCC (2007), em seu estudo, no hospital Universitário de Brasília mostraram que os acidentes de trabalho com perfurocortantes ocorreram principalmente, com mulheres da equipe de 
enfermagem responsáveis pela aplicação de drogas injetáveis, seguido de exposição percutânea, envolvendo sangue em agulhas com lúmen que não foram descartadas adequadamente. $O$ estudo, também relatou notificação de acidentes de outros profissionais, como dentistas.

Um dado relevante dos acidentes com material biológico é ter uma boa anamnese com pedidos de sorologia para HBV, HCV e HIV do paciente fonte e em situações, sem estes dados pode-se indicar um teste rápido para reduzir ansiedade profissional, uso desnecessário de terapia antirretroviral (TARV) e dar continuidade ao tratamento quando houver indicação para minimizar a possibilidade de infecção por HIV (COUTINHO AP, et al., 2004). Shimizu HE e Ribeiro EJGS (2002) mostraram que os profissionais de saúde frequentemente interrompem os medicamentos antirretrovirais devido a vários efeitos colaterais.

As sextas-feiras foram os dias com maior incidência de acidentes percutâneos, provavelmente devido aos altos níveis de estresse, falhas técnicas odontológicas, preocupações e ansiedade acumulada durante uma semana exaustiva de trabalho. Poucos estudos relatam o dia da semana como o de maior risco para a ocorrência de acidentes em odontologia (SANTOS KF, 2014).

Em contrapartida, encontramos referências de acidentes em hospitais, nas segundas-feiras pela manhã, onde há a troca de turno de trabalho, com maior desgaste profissional e maior manipulação de objetos perfurocortante, como troca de cateteres, agulhas, lâminas de bisturis e outros que muitas vezes, não sofrem descartes adequados e contribuem para os acidentes (MARZIALE MHP, et al., 2007).

Martins AMEL, et al. (2010) observaram que os acidentes ocorreram com instrumentos como brocas e sondas periodontais e o dedo foi a parte mais afetada pelos perfurocortantes, a fim de evitar os acidentes preconiza-se não reutilizar seringas e agulhas, ter maior atenção ao manusear instrumentos pontiagudos, não deixar brocas montadas em canetas de alta-rotação para proteger o profissional e a equipe odontológica.

Um fator de risco para acidentes, na odontologia é o reencape de agulhas, ainda realizado ao redor mundo por muitos profissionais que não seguem a conduta preconizada, como o descarte de objetos perfurocortantes e agulhas em caixa coletora própria, seguido de dispositivo que permita que a agulha seja separada e descartada sem que a outra mão possa interferir (MARTINS AMEBL, et al., 2010).

Os dedos das mãos foram os mais acometidos pelos acidentes com perfurocortantes e as lesões percutâneas foram as mais prevalentes (MAZUTTI JW, et al., 2018). No estudo de Santos KF (2014) a mão esquerda foi a mais afetada com relato de $48(46,7 \%)$ acidentes do GG e $21(52,5 \%)$ do GS, mostrando que a mão direita segurava a carpule como auxiliar, enquanto a mão esquerda segurava o protetor de agulhas, para se possibilitar o reencape, o que facilita a ocorrência de autoacidentes.

Dentre as medidas adotadas após o acidente, a expressão local foi à medida mais comum em 27 (31\%) das 87 exposições percutâneas no GG e $11(27,5 \%)$ do GS. Outras medidas profiláticas foram tomadas, no GG, como lavagem do local com água (77 - 74,8\%), sabonete (63-61,2\%) e uso de antisséptico (47 - 45,6\%), no local ferido (SANTOS KF, 2014).

O Ministério da Saúde (MS) recomenda a lavagem do local afetado com água e antisséptico e, para exposição de mucosas, deve-se fazer o enxágue com água ou solução salina estéril, além de evitar procedimentos que aumentem a exposição percutânea ou dérmica, como a expressão loca (BRASIL, 2006). No entanto, caso seja necessário fazer curativo compressivo ou sutura é indicado o uso de antissépticos, como medida imediata após o acidente (GRAZIANO KU, 2000).

As luvas fazem parte dos EPI que conferem proteção, diminuem risco de contaminação e evita contaminações cruzadas, portanto devem ser usadas todas as vezes que houver manipulação de tecidos, mucosas, sangue e saliva e ser descartáveis, de uso único com indicação de lavagem das mãos antes e após a retirada das luvas, com a intenção de reduzir riscos de infecção, embora haja um número considerável de profissionais que não o fazem mesmo que isso seja preconizado em escolas de odontologia (MELO TRNB, et al., 2020).

No estudo de Mazutti JW, et al. (2018) a lavagem das mãos é uma das principais medidas preventivas para evitar infecções e deve ser realizada antes e depois de cada procedimento odontológico, no início e final 
da jornada de trabalho, porém muitos estudantes não faziam de forma ideal o que mostrou a negligência na adoção de assepsia.

Izzetti R, et al. (2020) ressaltam que em tempos de COVID-19 a assepsia das mãos deve ser realizada com água e sabão, por 60 segundos seguida do uso de álcool a 60 a 85\%, antes da colocação de luvas. Recomenda-se que, além dos EPI utilizados na prática odontológica o uso de protetor facial, avental de polipropileno com mangas compridas, protetores para os pés e máscaras (N-95, PFF2 e PFF3) específicas. Protocolos de biossegurança profissionais, para procedimentos clínicos e espaço físico contribuem na contenção infecciosa e previnem danos (FARIA MHD, et al., 2020).

\section{CONCLUSÂO}

Os profissionais acidentados entrevistados tiveram seus acidentes, com material biológico, caracterizados epidemiologicamente, relataram maior adesão ao uso de EPI e mudanças comportamentais em relação à biossegurança. Nota-se, que há a necessidade de estudos que corroborem com prática odontológica, no sentido de prevenir, evidenciar os acidentes, mostrar o dia da semana de maior ocorrência, com a intenção de demonstrar a gravidade, a falta de notificações, tão prejudiciais para o exercício da profissão de forma segura e, por meio de aperfeiçoamentos em instituições, congressos, reforço nas disciplinas de graduação, os conceitos de biossegurança podem se tornar viáveis.

\section{REFERÊNCIAS}

1. ALMEIDA CAF, BENATTI MCC. Exposições ocupacionais por fluidos corpóreos entre trabalhadores da saúde e sua adesão à quimioprofilaxia. Revista da Escola de Enfermagem da USP, 2007; 41(1): 120-126.

2. AMATO A, et al. Infection Control in Dental Practice During the COVID-19 Pandemic. International Journal of Environmental Research and Public Health, 2020 Jul 2; 17(13): 4769.

3. ARTUZI FE, et al. Acidentes pérfuro-cortantes na Faculdade de Odontologia da Universidade Federal do Rio Grande do Sul. Revista da Faculdade de Odontologia de Porto Alegre, 2009; 50(2): 26-29.

4. BRASIL. Ministério da Saúde. Secretaria de Atenção a Saúde. Departamento de Ações Programáticas. Exposição a materiais biológicos. Brasília: MS, 2006. (Serie A. Normas e Manuais Técnicos - Saúde do Trabalhador, n. 3. Protocolo de Complexidades).

5. CAVALCANTE NJF, et al. Biossegurança. 2a ed. rev. ampl. São Paulo: SES; 2003.

6. COULTHARD P. Dentistry and coronavirus (COVID-19): moral decision-making. British Dental Journal, 2020; 228(7): 503-505.

7. COUTINHO AP, et al. Antiretroviral therapy indication post occupational exposure in university teaching hospital after introdution of rapid HIV antibody assay. In: 14th Annual Scientific Meeting the Society for Healthcare Epidemiology of America, 2004. Philadelphia, Pensylvania. Abstracts. Philadelphia: SHEA, 2004; 1: 133.

8. FARIA MHD, et al. Biossegurança em odontologia e COVID-19: uma revisão integrativa. Cadernos ESP Ceará, 2020; 14(1): 53-60.

9. FIELD A. Descobrindo a estatística utilizando o SPSS. Porto Alegre: ARTMED, 2009.

10. GABLER IG et al. Prevenção e ocorrência de acidentes com materiais perfurocortantes entre os profissionais da área odontológica da cidade de Vila Velha/ES. Revista Brasileira de Odontologia, 2012; 69(2): 174-179.

11. GRAZIANO KU, et al. Limpeza, desinfecção, esterilização de artigos e anti-sepsia. In: FERNANDES AT, editor. Infecção hospitalar e suas interfaces na área da saúde. São Paulo: Atheneu, 2000; 1: 266-305.

12. IZZETTI R, et al. COVID-19 transmission in dental practice: brief review of preventive measures in Italy. Journal of Dental Research, 2020; 99(9): 1030-1038.

13. KHALIL SS, et al. Occupational exposure to bloodborne pathogens in a specialized care service in Brazil. American Journal of Infection Control, 2015; 43(8): e39-41.

14. KOTZE MJ, LABUSCHAGNE W. A method of determining the presence of blood in and on a dental needle after the administration of local anesthetic. Journal of the American Dental Association, 2014; 145 (6): 557-562.

15. MARTINS AMEBL, et al. Adesão a protocolo pós-exposição ocupacional de acidentes entre cirurgiões dentistas. Revista de Saúde Pública, 2010; 44(3): 528-540.

16. MARZIALE MHP, et al. Acidentes com material biológico em hospital da Rede de Prevenção de Acidentes do Trabalho - REPAT. Revista Brasileira de Saúde Ocupacional, 2007; 32(115): 109-119.

17. MAZUTTI JW, et al. Acidentes perfurocortantes envolvendo material biológico: o dizer e o fazer de estudantes. Revista da ABENO, 2018; 18(4): 21-30.

18. MELO TRNB, et al. Avaliação do controle das medidas de biossegurança adotadas por acadêmicos de Odontologia. Revista Eletrônica Acervo Científico (REAC), 2020; 8: e2112.

19. MOYSÉS SJ. Políticas de saúde e formação de recursos humanos em odontologia. Revista da $A B E N O, 2003 ; 4(1)$ : 30-77. 
20. NOGUEIRA AS, et al. Prevalência e notificações de acidentes de trabalho com exposição a material biológico na odontologia. Revista Ciência Plural, 2016; 2(1): 102-119.

21. OLIVEIRA HR, RIBEIRO GM. A prevalência de acidentes com material perfurocortante na clínica. Trabalho de Conclusão de Curso (Bacharel em Odontologia) - Centro Universitário do Planalto Central Apparecido dos Santos, 2019; 7p.

22. SANTOS KF, BARBOSA M. COVID-19 e a Odontologia na prática atual. REAS Revista Eletrônica Acervo Saúde, 2020; 12(11): e5113.

23. SANTOS KF, CAVALCANTE NJF. Biossegurança e acidentes com material biológico na odontologia: considerações atuais. REAS Revista Eletronica Acervo Saude, 2021; 13(2): e6329.

24. SANTOS KF. Análise dos aspectos epidemiológicos dos acidentes ocupacionais, práticas de biossegurança e impacto na rotina de trabalho de cirurgiões-dentistas, após exposição a material biológico. Tese (Doutorado em Ciências) Coordenadoria de Controle de Doenças, Secretaria de Estado da Saúde de São Paulo, São Paulo; 2014.

25. SHIMIZU HE, RIBEIRO EJGS. Ocorrência de acidente de trabalho por materiais perfurocortantes e fluidos biológicos em estudantes e trabalhadores da saúde de um hospital escola de Brasília. Revista da Escola de Enfermagem da USP, 2002; 36(4): 367-375.

26. SILVA LN, et al. Atenção precoce e educação em saúde na atividade laboral: uma abordagem da infecção pelo HIV/Aids na odontologia do trabalho. DST - Jornal Brasileiro de Doenças Sexualmente Transmissiveis, 2011; 23(1): 34-39.

27. TIBÂES HBB, et al. Accidents at work from exposure to biological material contamination of viral hepatitis "B" and " $\mathrm{C}$ " in a Brazilian Capital. Occupational Diseases and Environmental Medicine, 2014; 2: 39-47. 